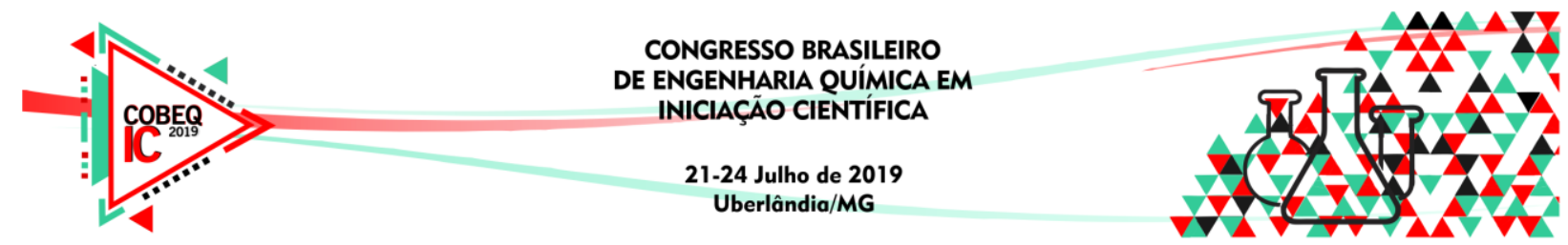

\title{
DESENVOLVIMENTO DE FILMES POLIMÉRICOS BIODEGRADÁVEIS PARA PRODUÇÃO DE MUDAS EM SUBSTITUTIÇÃO AO USO DE TUBETES
}

\author{
D. G. P. FERREIRA ${ }^{1}$, M. G. RODRIGUES ${ }^{1}$, V. M .M. MENDONÇA ${ }^{2}$, M. G. PEREIRA ${ }^{3}$ e \\ P. J. OLIVEIRA ${ }^{1}$ \\ ${ }^{1}$ Universidade Federal Rural do Rio de Janeiro, Departamento de Engenharia Química \\ ${ }^{2}$ Universidade Federal Rural do Rio de Janeiro, Programa de Pós-Graduação em Ciências \\ Ambientais e Florestais, Área de Concentração Silvicultura e Manejo Florestal \\ ${ }^{3}$ Universidade Federal Rural do Rio de Janeiro, Programa de Pós-Graduação em Agronomia \\ - Ciência dos Solos
}

E-mail para contato: paulojansenster@gmail.com

\begin{abstract}
RESUMO - Filmes poliméricos tem sido utilizado para diversas aplicações tecnológicas. Nesse trabalho misturas poliméricas a base de carboximetilcelulose (CMC), alginato, amido e goma Agar-agar foram testadas com vistas à produção de mudas para reflorestamento em substituição a tubetes de polietileno. Os resultados desse trabalho mostraram que as misturas contendo CMC foram as que apresentaram maior biodegradação no solo testado. Além disso, a presença dos filmes não afetou o desenvolvimento das mudas. Os resultados de miscrocopia ótica mostrou aspectos morfológicos diferentes para amostra tratadas com $\mathrm{CaCl}_{2} \mathrm{e}$ entre as diferentes composições estudadas. A amostra F4 foi aquela que apresentou morfologia na qual não foi possível distinguir a presença de fases.
\end{abstract}

\section{INTRODUÇÃO}

Misturas poliméricas têm sido utilizadas como uma estratégia vantajosa para preparação de novos materiais de engenharia, pois possibilita reunir e combinar, num único material, duas ou mais propriedades fisico-mecânicas desejadas para uma determinada aplicação tecnológica (Soares e Oliveira, 2003) Os polímeros sintéticos são um dos principais materiais de engenharia utilizados e dentre eles destacam-se: o polietileno (PE), e polipropileno (PP). Segundo Bolsoni (2001), o uso desses materiais tem gerado dois problemas: primeiro por ser de fonte não renovável, e o segundo pela quantidade de resíduos gerada no seu descarte. Esses impactos se tornam mais relevantes quando as aplicações tecnológicas são voltadas para agricultura e para o reflorestamento (Franchetti e Marconato, 2006). Piccoli et al, (2000), sugere a substituição dos polímeros sintéticos pelos biodegradáveis como alternativas para esse problema. $\mathrm{Na}$ agricultura e no reflorestamento, a utilização de polímeros biodegradáveis e biocompatíveis com a planta é essencial para o sucesso da tecnologia. Segundo Junior (2001), esses polímeros devem se degradar em contato com o solo pelo ataque microbiano, sob condições apropriadas ao meio ambiente. Nesse caso, a escolha do biopolímero a ser utilizado, dependerá do tipo de aplicação, produto desejado e condições ambientais. Segundo Junior et al. (2012), a 


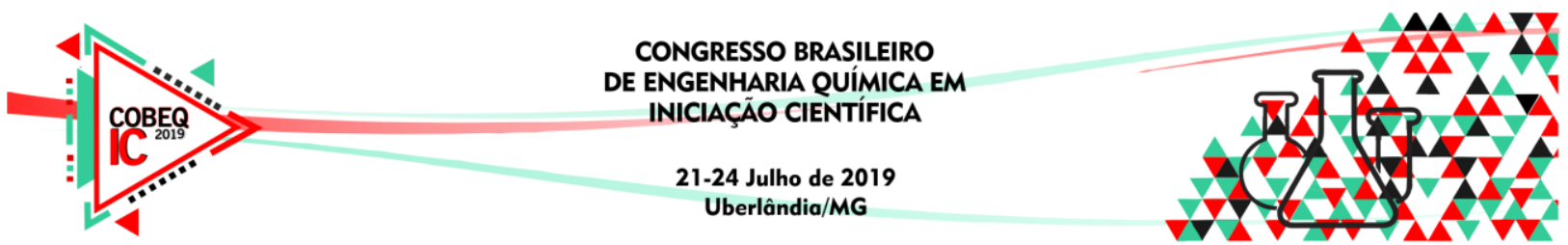

carboximetilcelulose (CMC) e o Alginato de sódio são biopolímeros utilizados na produção de filmes e géis para processos de encapsulação e liberação de princípios ativos; são usados na produção de filmes comestíveis e protetores e como agente de liberação controlada de pesticidas e nutrientes. Nos últimos anos, o amido tem sido utilizado em misturas com CMC para preparação de veículo de inoculação para agricultura. Secundo Junior et al. (2012), o uso do amido na produção inoculantes se baseia na sua capacidade de formar géis e seu uso como fonte de carbono para bactérias. Segundo Fani (2008), o ágar-ágar possui aplicação nas indústrias alimentícias, petroquímica, farmacêutica, de papel, têxtil, cosmética e na biotecnologia.

Nas aplicações voltadas para o reflorestamento, nos viveiros de produção de mudas são utilizados basicamente dois tipos embalagens para a produção das plantas: sacos plásticos e tubetes de PE e PP. Nesse caso se faz necessária a remoção da planta desses recipientes e, muitas vezes, no momento da plantação dessas árvores, esses materiais são esquecidos ou despejados de forma inadequada no solo, causando danos ao ambiente Cazotti (2001). Sendo assim, a busca por recipientes biodegradáveis é uma demanda atual. Nesse sentido, o objetivo desse trabalho é desenvolver filmes biodegradáveis a partir de misturas poliméricas biodegradáveis, combinando as propriedades físico-mecânicas de cada polímero, para utilização como embalagens para produção de mudas.

\section{Materiais e Métodos}

Para a preparação dos filmes foram utilizados os seguintes biopolímeros: Carboximetilcelulose (CMC), alginato de sódio (AS), amido solúvel, ágar ágar e cloreto de cálcio. A composição dos filmes é presentada na Tabela 1. As misturas foram preparadas pela dissolução dos polímeros CMC/AS/amido/ágar em água destilada à $90{ }^{\circ} \mathrm{C}$, sob agitação constante por 1 hora. Ao término, as soluções foram vertidas em placas de vidro e secas a temperatura ambiente por 7 dias.

Tabela1 - Formulações poliméricas do filmes

\begin{tabular}{ccccc}
\hline \multirow{2}{*}{ Biofilmes } & CMC & AS & \multicolumn{1}{c}{ Amido } & Ágar \\
\hline & \multicolumn{5}{c}{ (g) } \\
\hline F 1 & 4,75 & 4,75 & 0,5 & 0,05 \\
F 2 & 4,75 & 4,75 & 0,5 & 0,1 \\
F 3 & 5 & 5 & - & 0,05 \\
F 4 & - & 5 & 0,5 & 0,05 \\
\hline
\end{tabular}

Após a completa secagem, os filmes foram retirados da placa e separados para processo de reticulação. 


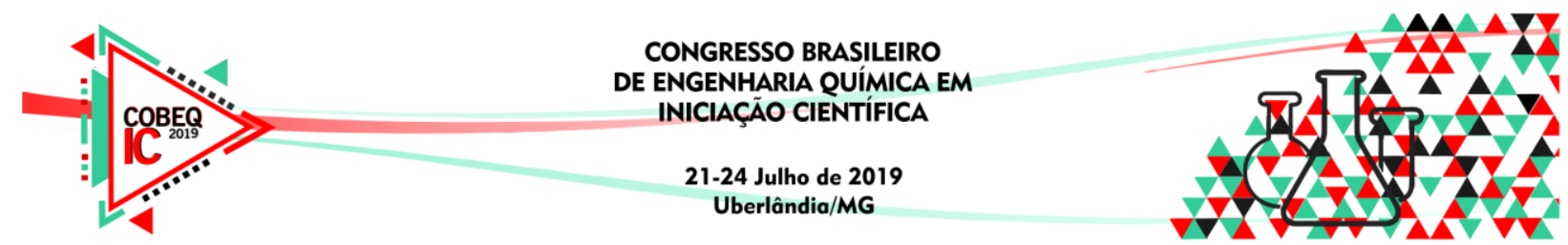

Figura 1 - Aparato usado para preparação do biofilmes

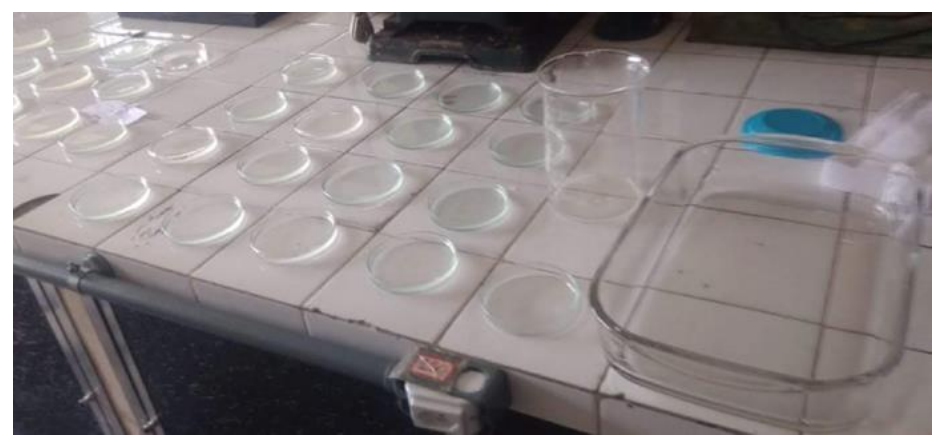

\subsection{Processo de reticulação e de biodegradação}

Os filmes poliméricos foram reticulados utilizado uma solução aquosa de $5 \% \mathrm{~m} / \mathrm{v}$, $\mathrm{CaCl}_{2}$. Os filmes foram imersos na solução reticulante por 30 minutos. Em seguida, os filmes foram secos a temperatura ambiente.

Os filmes reticulados com $\mathrm{CaCl}_{2}$, foram submetidos à biodegradação em solo de acordo com a metodologia descrita por Martucci e Ruseckaite (2009). A biodegradação foi avaliada através da perda de massa dos filmes, equação 1 , quando expostos à microbiota natural encontrada no solo. Foram preparados filmes com dimensões de: $16 \mathrm{~cm}$ de comprimento e $2 \mathrm{~cm}$ de largura que foram enterrados em vasos, à $14 \mathrm{~cm}$ de profundidade do solo utilizado na produção de mudas. Vasos com volume de 1,7 L (citros pote) foram preenchidos com terra e irrigados duas vezes ao dia para manutenção da umidade. Nos vasos, se utilizou os primeiros $20 \mathrm{~cm}$ de um Latossolo Vermelho - Amarelo eutrófico, com pH 6,2, contendo 45,6\% de argila, 47,5\% de areia e 6,9\% de silte. O acompanhamento da biodegradação dos filmes foi realizada após 7, 14, 21 e 28 dias. As amostras dos filmes foram retiradas do solo, lavadas em água, secas por 7 dias e pesadas.

$$
\text { Perda de massa }(\%)=\frac{\left(M_{t 0}-M_{t s}\right)}{M_{t 0}} \times 100
$$

Sendo $\mathrm{M}_{\mathrm{t} 0}$ e $\mathrm{M}_{\mathrm{ts}}$ as massas inicial e final da amostra, respectivamente.

Foram realizadas análises de microscopia óptica (MO) dos filmes reticulados com $\mathrm{CaCl}_{2}$ e não reticulados antes e após a exposição ao solo com 1, 2, 3 e 4 semanas.

\section{Resultados e Discussão}

$\mathrm{Na}$ análise visual, todos os filmes apresentaram aspectos homogêneos, antes e após a reticulação, Figura 2. Os filmes F3 e F4 se apresentaram transparentes e flexíveis, enquanto que os filmes F1 e F2 se mostraram mais quebradiços.

Os testes de solubilidade em água a quente e fria mostraram que todos os filmes não reticulados são solúveis, enquanto que os tratados com $\mathrm{CaCl}_{2}$ ficaram totalmente insolúveis, uma característica desejada para os recipientes no período de produção de mudas em viveiro. 


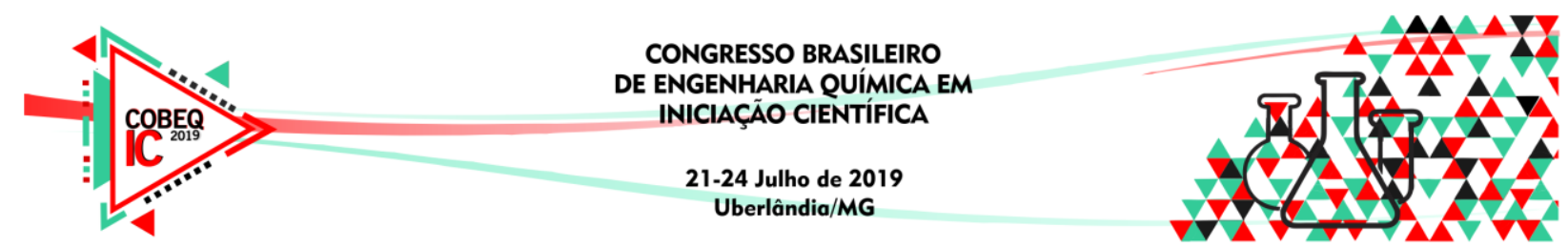

A Figura 3 apresenta o resultado da perda de massa dos filmes após a biodegradação em solo. As amostras F1, F2 e F3 apresentaram uma acelerada biodegradação em 7 dias de ensaio, $46 \%, 43 \%$ e $41 \%$, respectivamente. Partir de 7 dias observa-se uma lenta degradação de todas as amostras, alcançando no final de 28 dias uma perda de massa de $55 \%, 52 \%$ e $50 \%$, respectivamente.

Entretanto, O filme F4 não apresentou degradação significativa, 4\%, filme que não contém CMC. Sendo assim, os resultados sugerem que a presença do CMC na mistura colabora para biodegradação do filme. É interessante notar que o teor de massa de CMC nas misturas é de cerca de 50\% (Tabela 1).

Figura 2 - Imagem dos filmes biodegradáveis

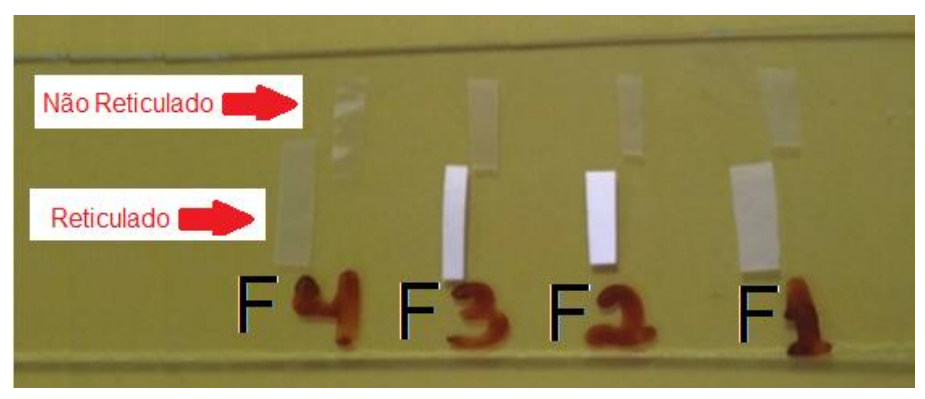

Figura 3 - Variação da perda de massa dos biofilmes com o tempo

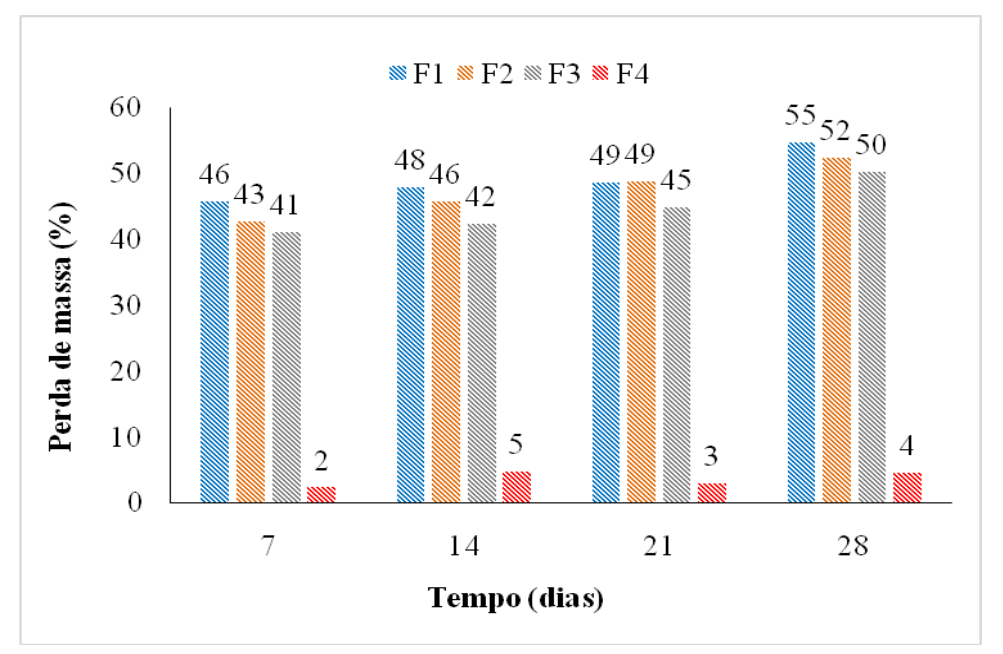

A Figura 4 apresenta os resultados de microscopia ótica dos filmes antes e após a reticulação. As amostras reticuladas com $\mathrm{CaCl}_{2}$ apresentam morfologia bastante distinta das amostras não reticuladas. As micrografias das amostras F1, F2 e F3 não reticuladas revelam a presença de rugosidades na sua superfície. Esse aspecto rugoso foi bastante reduzido quando o filme foi reticulado com $\mathrm{CaCl}_{2}$. Entretanto, o aspecto rugoso não é observado na micrografia do filme F4, filme que apresentou elevada resistência a degradação. 


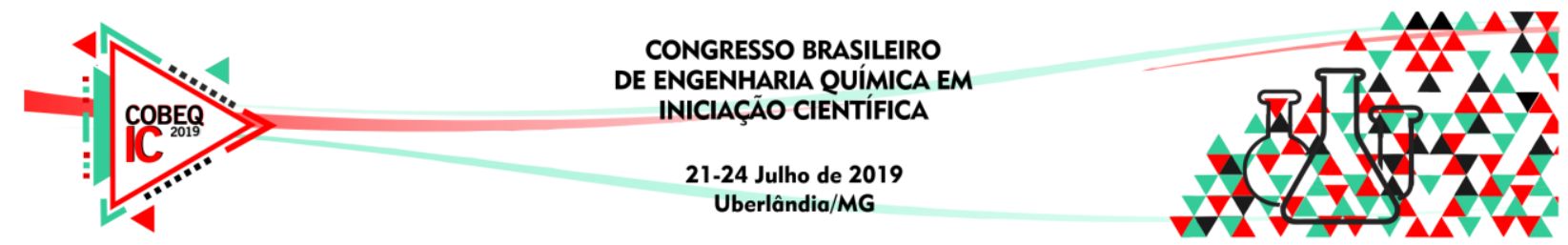

A morfologia apresentada pela mistura F3 se destaca pela presença de domínios com aparência esférica na sua superfície. Essa amostra não contém amido. Conforme discutido na introdução desse trabalho, o amido pode atuar como plastificante na presença de alguns polímeros. Sendo assim, a sua ausência pode prejudicar a compatibilidade dos componentes favorecendo a separação de fases, o que pode justificar a presença de domínios na superfície desse filme.

Figura 4 - Microscopia óticas dos biofilmes
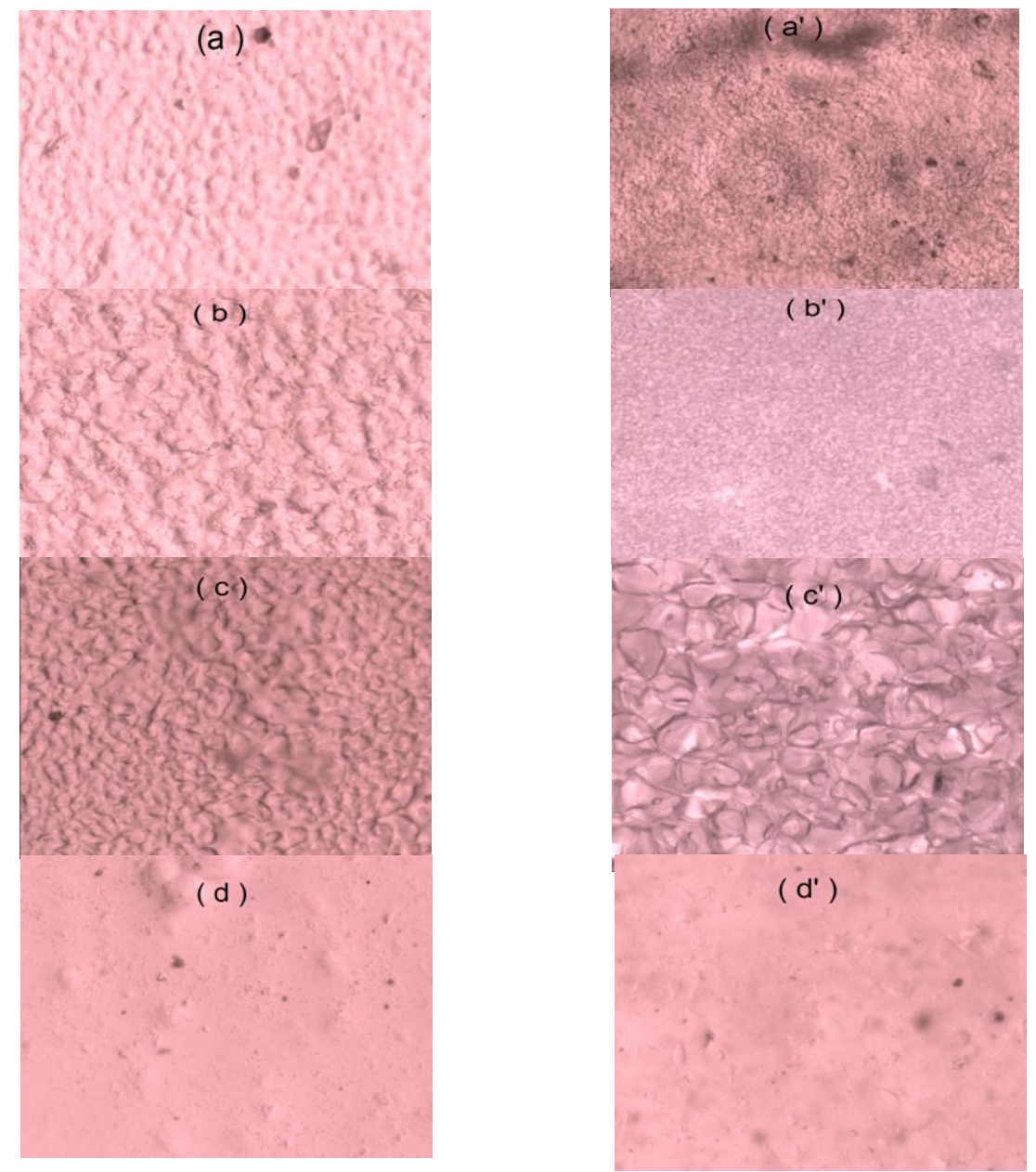

(a-d) filmes F1,F2,F3, F4 Não reticulada; (a'-d') filmes F1,F2,F3, F4 reticulada com CaCl2,

\section{Conclusão}

Os resultados obtidos nesse trabalho permitiram concluir que a estratégia de usar combinação dos quatros polímeros para preparação de filmes biodegradáveis foi apropriada pois foi possível preparar misturas biodegradáveis que mantiveram estabilidade dimensional 


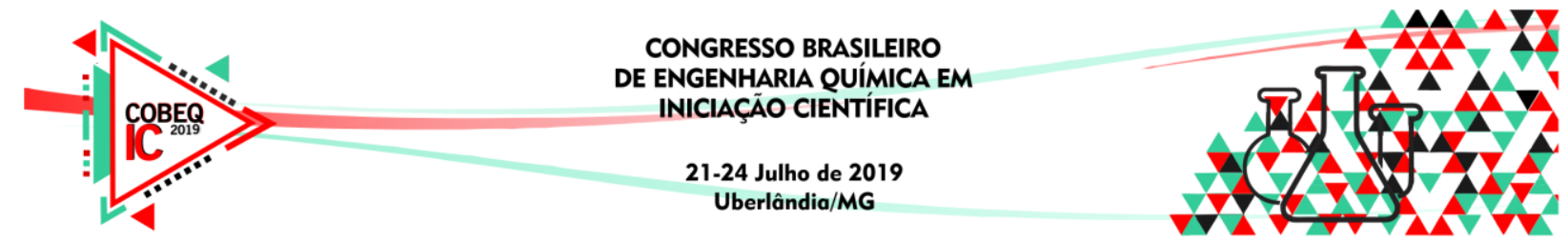

para produção dos filmes e não interferiram no crescimento das mudas (não apresentado). Os resultados mostram que a presença de CMC favorece a biodegradação no solo usado, embora o amido seja conhecido como uma boa fonte de carbono para bactérias. Os resultados também permitiram verificar que a amostra sem CMC, F4, foi aquela que não apresentou degradação dentro do tempo de estudo, sugerindo que a composição polimérica a ser escolhida depende das características do solo a ser aplicado e as biotas presentes nesse solo.

\section{REFERÊNCIAS}

BOLSONI, E. Estudo da reprocessabilidade do polietileno de baixa densidade. Dissertação (Mestrado). Universidade Estadual de Campinas - UNICAMP, Campinas, 76.f, 2001.

CAZOTTI, M. M. - Resíduos de Rochas Ornamentais Associados à Compostagem e o Desenvolvimento do Pinhão Manso, XIX Jornada de Iniciação Científica do CETEM, 2011

FANI, M.. Agar-Agar - O mais antigo fitocolóide. Aditivos \& Ingredientes. São Paulo: Editora Insumos Ltda., v.56, mai/jun. 2008. 31p.

FRANCHETTI, S.M.M; MARCONATO, J.C. Polímeros biodegradáveis - uma solução para diminuir a quantidade dos resíduos plásticos. Química Nova, São Paulo, v. 29, n. 4, p. 811816, 2006.

JUNIOR, J. C. A. Uso de tubete e de minitubete de compósito de polihidroxibutirato mais pó de madeira na produção e no plantio de mudas seminais e clonais de eucalipto. Tese (Doutorado), ESALQ/USP, Piracicaba, 128 f. 2011.

JUNIOR, F. P. I; Oliveira, P. J. ; Rumjanek, G. N. ; XAVIER, G. R. Performance of polymer compositions as carrier to cowpea rhizobial inoculant formulations: survival of rhizobia in pre-inoculated seeds and field efficiency. AFRICAN journal of Biotechnology, v. 11, p. 2945-2951, 2012.

MARTUCCI, J. F.; RUESECKAITE, R. A. Biodegradation of three-layer laminate films based gelatin under indoor soil conditions. Polymer Degradation and Stability, v. 94, n. 8, p. $1307-1313,2009$.

PICCOLI, R.A.M.; QUIROZ, L.H.C.; FLEURY, A.; MATTOS, M.N.; OLIVEIRA, V.; BONOMI, A. Otimização da produção de polihidroxibutirato por via fermentativa, baseada num modelo matemático cibernético. In: CONGRESSO BRASILEIRO DE ENGENHARIA QUÍMICA Águas de São Pedro. Anais. Campinas: Universidade de Campinas, 2000. res. n. 839. 1 CD-ROM., 13., 2000.

SOARES, B. G; OLIVEIRA, P. J. Efeito da compatibilização da mistura NBR/EVA sobre sua morfologia de fase co-contínua. Polímeros: Ciência e Tecnologia, v 13(1), p. 28-35, 2003.

TURBIANI, F. R. B.; KIECKBUSH, T. G.; GIMENES, M. L. Processo de produção de filmes plásticos biodegradáveis de alginato e sódio - controle da reticulação. In: Anais do $10^{\circ}$ Congresso Brasileiro de Polímeros, Artigo, Foz do iguaçu, 2009.

SOUZA, C. R. Processos orgânicos. São Paulo: Editora Silva, 1996. 